\title{
Interstitial Lung Diseases and Air Pollution: Narrative Review of Literature
}

\author{
Nishtha Singh $\cdot$ Sheetu Singh D
}

Received: September 25, 2020 / Accepted: January 29, 2021 / Published online: March 10, 2021

(c) The Author(s) 2021

\begin{abstract}
Air pollution has been associated with respiratory diseases such as chronic obstructive pulmonary disease (COPD) and lung malignancies. The aim of this narrative review is to analyze the current data on the possible association between air pollution and interstitial lung disease (ILD). There are multiple studies showing the association of ILD with air pollution but the mechanism remains unclear. Although some of the environmental factors have been associated with idiopathic pulmonary fibrosis (IPF), hypersensitivity pneumonitis (HP), and pneumoconiosis, data about other ILDs are scarce and not well known. Air pollution as an etiology for ILD may act in multiple ways, leading to disease pathogenesis or exacerbation of underlying ILD. Clinical implications of this association are manifold; limiting the exposure to poor-quality air could possibly reduce the fall in lung functions and the risk of acute exacerbations of the underlying ILD.
\end{abstract}

N. Singh

Department of Respiratory Medicine, Asthma

Bhawan, Jaipur, India

S. Singh $(\bowtie)$

Department of Chest and Tuberculosis, Institute of Respiratory Disease, SMS Medical College, Jaipur, India

e-mail: sheetusingh@yahoo.co.in

\section{PLAIN LANGUAGE SUMMARY}

Air pollution is a major problem worldwide. Pollutants are vented out in the ambient air by sources like vehicular fume exhaust, factory pollution, combustion by burning of biomass fuels, and indoor pollution. The probable constituents responsible for respiratory diseases are particulate matter 2.5 and 10, nitrogen dioxide $\left(\mathrm{NO}_{2}\right)$, and ozone present in polluted air. The role of these pollutants in pathogenesis of interstitial lung disease (ILD) is complex. The probable pathways include: oxidative stress, inflammation, and telomere shortening. ILD is a heterogeneous group of diseases, and the effect of pollution on various types is also varied. Air pollution has been associated with poor lung function and exacerbations in idiopathic pulmonary fibrosis (IPF), increased prevalence of hypersensitivity pneumonitis (HP), and presence of pulmonary fibrosis in healthy adults and children. The incidence rate of IPF has also been associated with pollutant levels such as $\mathrm{NO}_{2}$. Thus, patients with ILD should be cautious during bad-quality air days and they are advised to avoid outdoor activities and use facemasks during this period.

Keywords: Air pollution; Idiopathic pulmonary fibrosis; Interstitial lung diseases; Particulate matter 


\section{Key summary points}

Particulate matter, $\mathrm{NO}_{2}$, and $\mathrm{O}_{3}$ are the culprit pollutants leading to respiratory diseases.

HP: The proportion of HP cases increased with higher levels of air pollution in several Indian cities.

IPF: Air pollution has been associated with lower FVC, accelerated decline of FVC, and acute exacerbations in patients with IPF.

ILA: Also associated with increased risk of having ILA in both adults and children.

Possible mechanism: Air pollution $\rightarrow$ oxidant stress, inflammatory response and telomere shortening $\rightarrow$ fibrotic pathway.

Exposome should be evaluated to ascertain the cause of pulmonary fibrosis.

Patients with ILD should avoid strenuous exercise during bad-quality air days and use facemasks.

\section{DIGITAL FEATURES}

This article is published with digital features, including a summary slide, to facilitate understanding of the article. To view digital features for this article go to https://doi.org/10.6084/ m9.figshare.13656821.

\section{INTRODUCTION}

Interstitial lung diseases (ILD) are a heterogenous group of diseases that have varied etiologies, presentations, and treatment strategies. The diseases presenting as ILDs have diverse causes but often trigger irreversible fibrosis leading to hypoxemia, respiratory failure, and death. Causal association should be sought after in ILD, as removal from inciting antigen is vital to stop disease progression. Various environmental factors have been held responsible for specific types of ILD such as hypersensitivity pneumonitis (HP), idiopathic pulmonary fibrosis (IPF), and pneumoconiosis (asbestosis, silicosis) [1]. The causes of HP include microbes, molds, animal proteins, plant proteins, and organic and sometimes small molecular weight inorganic chemicals [1]. Pneumoconiosis comprises diseases caused by inhalation of different dusts for e.g., silica particles in silicosis, asbestos particles in asbestosis, and cotton fiber dust particles in byssinosis [1]. Though IPF has an unknown etiology, environmental risk factors such as cigarette smoking and exposure to metal or wood dust and viral infections have been known to predispose to IPF $[2,3]$.

Air pollution leads to death in one in eight people worldwide, and half of these are attributed to outdoor pollution (urban and rural) [4]. Around $92 \%$ of the world's population resides in areas that are more polluted than the World Health Organization's (WHO's) pollution target of PM2.5 $<10 \mu \mathrm{g} / \mathrm{m}^{3}$ [5]. It has been estimated that worldwide around 69.7 million disabilityadjusted life years (DALY's) are lost to outdoor air pollutant exposure [6]. Air pollution has been associated with various respiratory and non-respiratory diseases such as stroke, asthma, pneumonia, heart diseases, dementia, and diabetes [7-10]. Respiratory ailments such as obstructive airway diseases and non-respiratory ailments including cardiovascular diseases and brain hemorrhage have been associated with air pollution $[9,10]$. New evidence has emerged with regards to the etiological role of air pollution in the pathogenesis of ILD [11].

\section{Aim}

We aim to do a narrative review of the literature regarding the association of various types of ILDs with ambient air pollution levels and the air pollutants leading to ILD. The possible pathogenesis the clinical and future research implications would be analyzed. 


\section{METHODS OF LITERATURE SEARCH}

Studies analyzing the effect of exposure to air pollution have been conducted by following up the subjects with lung radiology and spirometry. Multicenter prospective longitudinal cohort studies have also shown an association of particulate matter with exacerbation and mortality in patients with IPF. We searched PubMed using the terms "air pollution" or "pollution" and "interstitial lung diseases" or "pulmonary fibrosis" or "diffuse parenchymal lung disease" or "idiopathic pulmonary fibrosis" or "IPF" or "hypersensitivity pneumonitis" for articles published up to August 5, 2020 in the English language. We did a narrative review of the literature of the search results obtained. This article is based on previously conducted studies and does not contain any studies with human participants or animals performed by any of the authors.

\section{CONSTITUENTS OF AIR POLLUTION}

Air pollution consists of hazardous biological, chemical, and particulate matter (PM) present in the air. Rural air is contaminated by burning biomass (either wood or dung for cooking or burning crops in fields) and urban air is contaminated by vehicular exhaust. Combustion of fossil fuels (petrol, gasoline, diesel) in engines and coal in power stations form the major components of urban air pollution. These noxious gases get mixed with particles generated from construction, rubber tires, molds, pollen, bacteria, drilling of sand or salt, and metals. This process eventually leads to the production of PM comprising of an amalgam of solids, liquids, and vapors. The air pollutants associated with significant health adverse effects include $\mathrm{PM}$, nitrogen dioxide $\left(\mathrm{NO}_{2}\right)$, other oxides of nitrogen, ozone $\left(\mathrm{O}_{3}\right)$, sulfur dioxide, carbon monoxide, and lead [12].

The PM adversely affects human health, ecosystems, the weather, and the visibility [13]. It is postulated that inhalation of fine PM leads to increased morbidity and mortality [14]. There are numerous particles which remain suspended in air and can be grouped as "total suspended particles (TSP)". These particles have an aerodynamic diameter, " $\mathrm{d}$ ", of less than $100 \mu \mathrm{m}$ [15]. The depth of absorption into the human body varies according to the PM size and can be further divided into fractions according to the diameter d: PM10, fine PM, and ultra-fine PM. PM larger than $10 \mu \mathrm{m}$ gets deposited in the nose and upper airways. PM-10 or coarse PM has a diameter of $<10 \mu \mathrm{m}$, implying that it can pass through a filter with pores $10 \mu \mathrm{m}$ in size, and settle in the bronchi. Fine PM (PM2.5) with a particle size $<2.5 \mu \mathrm{m}$ can pass through a filter with $2.5-\mu \mathrm{m}$ pores and can reach up to the alveoli. The ultra-fine PM has particle size $<0.1 \mu \mathrm{m}$ and reach to the alveoli and may cross over to the bloodstream [16].

The PM exert their toxicity both directly and indirectly by initiating free radical reactions in the cells and tissues. Prolonged exposure also leads to oxidative stress, telomere erosions leading to chronic diseases, and increased mortality. Their toxicity is enhanced by concomitant pollutants such as $\mathrm{NO}_{2}, \mathrm{O}_{3}$, and host factors determining the site of deposition. $\mathrm{NO}_{2}$ is produced by fossil fume combustion predominantly from vehicular exhaust and is used as a surrogate marker to quantify exposure to the same. It reacts with other innocuous compounds to form toxic compounds. It can combine with moisture and ammonia to form a particle that can penetrate deep in the respiratory system and activate an active inflammatory response in the lungs [17-19]. It can also combine with heat, organic compounds, and ultraviolet (UV) radiation to produce $\mathrm{O}_{3} . \mathrm{O}_{3}$ induces airway inflammation, hyper reactivity, and modifications in the immunoregulatory proteins [20-23]. It increases the risk of asthma exacerbations. Sulphur dioxide is generated predominantly from combustion of contaminated fossil fuels, especially coal-fired power factories.

\section{AIR POLLUTION AND LUNG TRANSPLANTATION}

In a cohort study of patients who underwent lung transplantation, it was found that 
proximity to roads with high traffic air pollution levels was associated with raised inflammatory markers, increased incidence of bronchiolitis obliterans syndrome, and death [24]. Long-term exposure to air pollution from traffic has been associated with higher risk of chronic lung allograft dysfunction (CLAD) in patients not taking macrolides [25]. A cohort of 5707 patients was formed from 13 lung transplant centers in ten countries in Europe. They used land-use regression models to quantify PM10 levels at residential areas of patients and also the traffic exposure by quantifying the distance of place of residence to major road. The CLAD and mortality of these patients was also associated with distance from major roads. However, the study was limited by missing variables and modeled PM data with varied time frame from the point of residence for the patients. Another study was conducted on a cohort of 520 lung transplant recipients. The lung function of these patients was measured every 6 months [26]. It was found that lower FVC\% predicted was associated with exposure to higher levels of PM10, PM2.5, and $\mathrm{NO}_{2}$ in the past year. This adverse effect was stronger in cases of patients not taking macrolides. PM10 levels were also associated with lower FEV1.

\section{INTERSTITIAL LUNG DISEASES (ILDS)}

Similarly, it has been postulated that air pollution increases the risk of developing interstitial fibrosis (Table 1). Environmental exposure to organic antigens or dust has been involved in the etiopathogenesis of few ILDs. These include $\mathrm{HP}$, silicosis, asbestosis, berylliosis, and smoking-related ILDs. Factory work and metal and wood dust exposure have been associated with the development of IPF [27-30]. Furthermore, cigarette smoking has been conclusively found to be associated with IPF through induction of profibrotic pathways in the body [27-30]. The organic and chemical agents present in occupational exposures and tobacco smoke have similarities to the PM present in ambient air pollution. There is a possibility that PM of air pollution also causes inflammation, deranged immune reactions, and subsequently fibrosis. Air pollution and cigarette smoke both have similar compositions and are sources of PM and inflammable organic compounds, which may be responsible for adverse health outcomes.

Table 1 Association of various lung diseases with air pollutants

\begin{tabular}{llll}
\hline S. no & Disease & Air pollutant & Parameter \\
\hline 1 & Idiopathic pulmonary fibrosis (IPF) & Ozone, $\mathrm{NO}_{2}, \mathrm{PM} 2.5, \mathrm{PM} 10$ & Fall in FVC \\
2 & & & Acute exacerbations \\
3 & Hypersensitivity pneumonitis (HP) & $\mathrm{PM} 2.5$ & Incidence \\
4 & Interstitial lung abnormality (ILA) & $\mathrm{PM} 2.5$, ozone & Incidence \\
& Lung transplant & PM10, PM2.5, $\mathrm{NO}_{2}$ & Graft rejection \\
& & & Bronchiolitis obliterans \\
& & & Fall in FVC \\
\hline
\end{tabular}

$\mathrm{NO}_{2}$ nitrogen dioxide, $P M$ particulate matter, $F V C$ forced vital capacity, COVID-19 coronavirus disease of 2019 


\section{AIR POLLUTION AND IPF}

Worldwide, IPF constitutes the most common and severe form of ILD with a median survival of 24-36 months [31]. The two outcome measures deciding survival in IPF include the lung function that is forced vital capacity (FVC) and acute exacerbations. Acute exacerbation is defined as worsening dyspnea with concomitant new parenchymal shadows (including ground glass shadows or consolidation) on high-resolution computed tomography (HRCT) and is an event associated with poor outcomes. There have been few studies postulating the role of air pollution in either the pathogenesis of IPF or exacerbation of pre-existing IPF [11, 32]. A significant association between PM10 levels and the rate of decline in their FVC was documented in 135 patients with IPF in a single-center cohort study [11]. A 1-unit increase in PM10 leads to $46 \mathrm{cc} /$ year additional decline in $\mathrm{FVC}$ $(p<0.05)$. However, the study was limited by selection bias, environmental confounders, and reliance on regional pollutant monitoring centers. Both $\mathrm{O}_{3}$ and PM 2.5 have been found to accelerate the natural course of the disease as well as exacerbations [32]. Another study showed a positive correlation of acute exacerbations with short-term exposure of environmental $\mathrm{O}_{3}$ levels [33]. They studied data from a South Korean group of 436 IPF patients and found a positive correlation between increased levels of $\mathrm{O}_{3}$ and $\mathrm{NO}_{2}$ (including mean levels, maximum levels, and the number of exceedances above accepted standards) and acute exacerbations of underlying IPF [33]. However, this was a retrospective analysis of data and the pollutants data again were collected from regional monitoring stations. Thus, the individual exposure to pollutants varied depending on the time the subject spent indoors or traveled to other places. Mortality in IPF patients has been found to be significantly associated with long-term exposure to PM10 and PM2.5 levels $(p<0.01)$. Pre-publication recent data of 325 patients of IPF found that lung function decline was evident in those patients exposed to air pollution [34]. The degree of lung function decline varied according to the type of air pollutant, possibly suggesting the varied pathways adopted by different pollutants to manifest diseases. A more recent systematic review even analyzed studies regarding the effect of air pollution on ILD. They found that outcomes of IPF and fibrotic ILD like mortality and exacerbations in all the studies were associated with ambient air pollutant levels [35]. The review admitted that there was heterogeneity in the study designs. Also, the exposure quantification was not accurate in the studies, as data about pollutants were captured through regional monitoring centers with varied distances from the residence. Conti et al., in their retrospective analysis of data from Lombardy, Italy, studied the correlation of air pollution with the incidence of IPF [36]. They found a positive significant correlation between air pollution levels and incident cases of IPF. The study relied on hospital records for documenting the incident cases, thus errors in disease coding could have occurred. Moreover, IPF patients who did not present to hospitals would have been missed from the study pool. In a small prospective study of 25 IPF patients, home spirometry was used to follow up the patients [37]. It was observed that lower FVC levels were associated with higher $\mathrm{NO}_{2}$ levels, but the weekly changes in FVC did not depend on air pollution exposure. The small sample size and limited followup of the study failed to capture the acute exacerbations of IPF; thus, remained the limitations of the study.

Though IPF is essentially an idiopathic disease with no known cause, the possible link with air pollution may help in better understanding the pathogenesis of this complex disease. There are a few caveats in this possible association. Other ILDs are often misdiagnosed as IPF, so the association of air pollution with IPF may be spurious. Second, air pollution may exacerbate all ILDs irrespective of their subtypes.

\section{AIR POLLUTION AND HP}

Data to decipher the possible association between HP and ambient air pollution are scant. $\mathrm{HP}$ is a multifactorial disease with 
environmental factors being the foremost causative agents. The first and second hit hypothesis has been proposed to explain the etiopathogenesis of HP [38]. "First hit" is the genetic framework of a person that predisposes the individual to develop the disease. "Second hit" is the environmental exposure that triggers the development of HP in individuals with the inherent first hit. The term "facilitators" has been proposed for agents that predispose to the second hit such as viral infections, pesticide exposures, and possibly air pollution. Air pollutants, particularly PM, may cause an inflammatory response in the smaller airways leading to retention of the inciting antigen in the alveoli leading to the disease and its manifestations.

The incidence of HP varied from 2.6 to $6.4 \%$ depending on the country, region, and type of study [39-41]. The high prevalence of cases of HP in India (47\%), led the authors of the ILD India registry to correlate the number of HP cases with the ambient air pollution levels, which were much higher in the country as compared to the rest of the world [42]. The data from patients living in urban areas from 19 centers across 11 cities from ILD India Registry were retrospectively analyzed [43]. The PM2.5 and 10 levels were obtained from the data provided by state pollution boards to WHO. A strong positive correlation was found between the PM2.5 levels and number of HP cases in these cities $(r=0.64, p=0.03)$. A 1-unit increase in PM2.5 level was found to be associated with a $7 \%$ increased risk of developing HP as compared to other ILDs. The implications of this are manifold, as HP is a reversible disease in the early stages, reduced exposure to the inciting antigen as well as polluted air could possibly prevent disease progression. However, the limitations of the study included retrospective study design, missing data, and distance of patient residence from the monitoring centers.

\section{AIR POLLUTION AND INTERSTITIAL LUNG ABNORMALITY (ILA)}

Interstitial lung abnormality (ILA) refers to asymptomatic patients with pulmonary fibrosis documented on HRCT performed for ancillary reasons. Large community-based studies have been conducted on healthy individuals to understand the effect of air pollution on the airways and lung parenchyma. A cross-sectional study conducted on 249 healthy children (230 children residing in highly polluted areas in southwest Mexico City, 19 residing in lower polluted areas in Tlaxcala) found a significant association between interstitial markings and hyperinflation on chest radiography with PM2.5 and $\mathrm{O}_{3}$ levels $(p<0.001$ and $p<0.001$, respectively) [44]. The Mexico children were chronically exposed to $\mathrm{O}_{3}$ levels above the set target of air quality for an average of $4.7 \mathrm{~h}$ per day and also to PM2.5 above the annual standard. The most common abnormalities seen on chest radiograph and HRCT were hyperinflation, reticular shadow, air trapping, and nodular shadows. They concluded that higher PM2.5 and $\mathrm{O}_{3}$ exposures were associated with abnormal chest radiographic and spirometric findings. However, follow-up of these children was not performed to assess whether they had become symptomatic over subsequent years. Analysis of the pathological specimens such as bronchoalveolar lavage fluid or biomarkers in the blood was not studied to validate the findings. HRCT was also available for limited number of children rather than the whole cohort of subjects.

The Multi-Ethnic Study of Atherosclerosis (MESA) Air-Lung Study included 6813 community residents that were followed up for 10 years [45]. In this prospective cohort study, a 40 parts per billion (ppb) increase in $\mathrm{NO}_{2}$ was associated with 1.62-fold increase in ILA and a 5-unit increase in PM2.5 was associated with $0.54 \%$ per year increase in high attenuation areas on HRCT. A study on Framingham Heart Study participants found that an increase in elemental carbon of $0.14 \mu \mathrm{g} / \mathrm{m}^{3}$ was associated with 1.27 (95\% CI 1.04 to 1.55$)$ times greater odds of ILA and 1.33 (95\% CI 1.00 to 1.76$)$ times greater odds of ILA progression [46]. Both of these cohort studies were thwarted with confounder bias. ILA on CT scan is often a finding of cardiogenic pulmonary edema, obesity, infection, and atelectasis. Thus, essentially it may have not been ILD but secondary manifestation of 


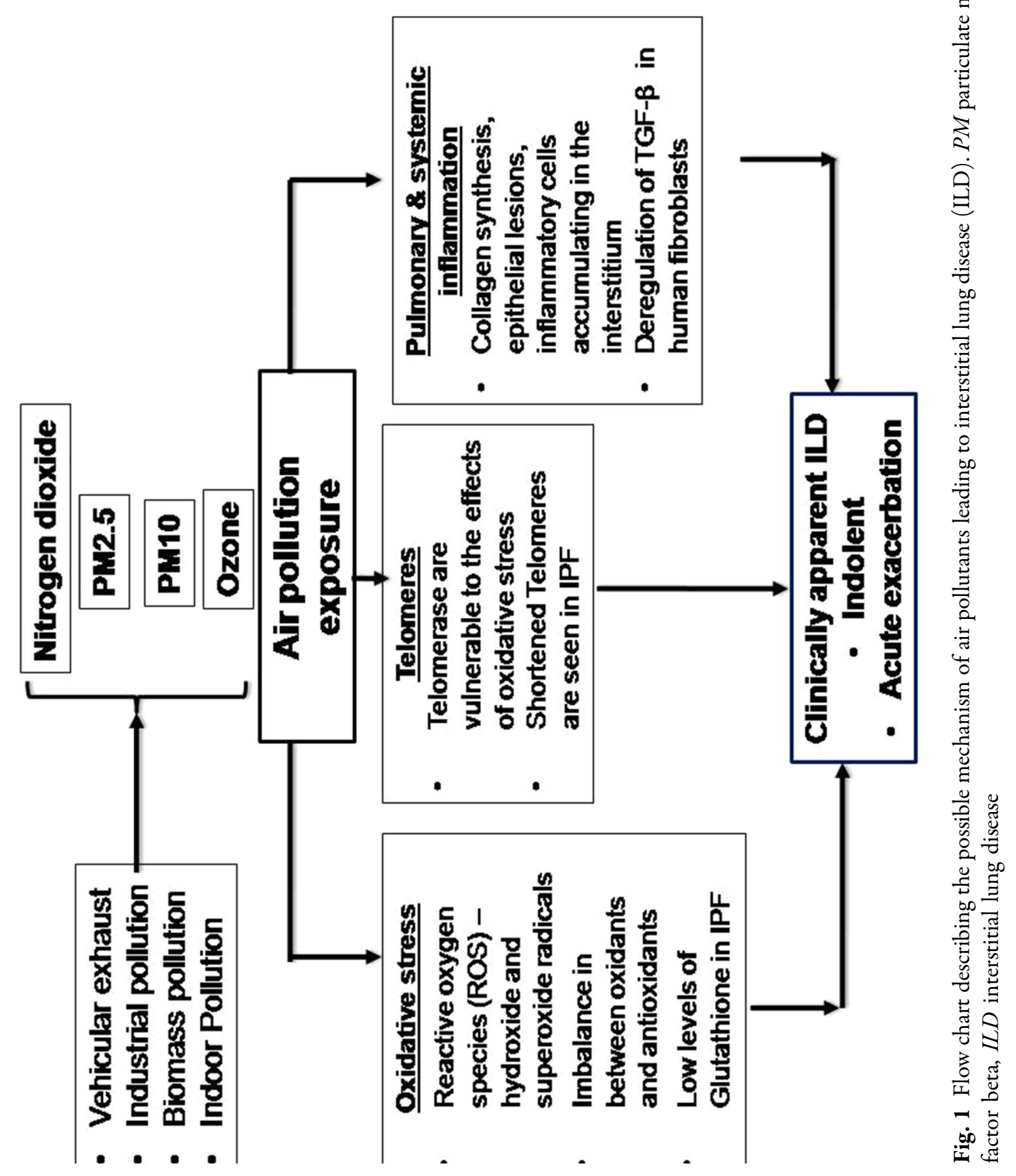


other diseases. The second limitation is the lack of follow-up of these patients on whether they developed clinical ILD in the future. Despite these limitations, pollution was associated with ILA, which could be a pre-clinical stage of ILD.

Thus, not only is air pollution associated with documented cases of ILD, but it may be associated with subclinical or antecedent cases of pulmonary fibrosis, which occur much before the development of actual symptoms.

\section{PATHOPHYSIOLOGICAL MECHANISMS}

The pathogenetic mechanism of air pollution leading to ILD is complex (Fig. 1). ILD is not a single disease but a group of diseases, and thus the pleiotropic effects of air pollutants would be varied depending on the genetic predisposition, concomitant exposures, and other socio-demographic variables. In vitro studies have shown that rats and monkeys exposed to high $\mathrm{O}_{3}$ have increased collagen deposition in their lungs $[47,48]$. Studies conducted in healthy volunteers exposed to intermittent air pollutants like $\mathrm{NO}_{2}$ and $\mathrm{O}_{3}$ showed both respiratory and systemic inflammation $[18,19]$. A similar pattern has been observed in epidemiological studies in healthy subjects with short-term exposures to high air pollutant levels $[49,50]$.

Exposure to air pollution produces oxidative stress, which triggers production of reactive oxygen species (ROS) such as hydroxide radical and superoxide anions [50-52]. These oxidants are counter-balanced by antioxidants. In ILD, the increased levels of ROS overwhelm the antioxidants stores and in turn the antioxidants cannot eradicate them, thereby leading to inflammation and fibrosis in the lung parenchyma. It has also been seen that patients of IPF have deficient levels of antioxidant glutathione in their lower respiratory tract, predisposing them to oxidative stress [53]. Despite this hypothesis, the role of antioxidant drug $\mathrm{N}$ acetyl cysteine (NAC) has not been proven in ILD. Randomized control trials have failed to show any benefit in terms of reducing the annual decline of FVC by NAC versus placebo in patients with IPF [54].
The second possible mechanism of air pollution leading to pulmonary fibrosis involves the telomeres. Telomeres are non-coding genetic sequences present at the end of the chromosomes; their role is to protect the genetic information carrying DNA rather than coding. They are susceptible to oxidative stress $[52,55]$. They withstand acute oxidative stress but shorten on chronic exposures. Shortened telomeres have been noted in IPF but shortening of telomeres was not genetic in these studies, thereby implying environmental causes $[56,57]$.

The third mechanism, of air pollution leading to parenchymal involvement, is inflammatory. Studies have shown that the transforming growth factor beta (TGF- $\beta$ ) pathway in the human fibroblasts gets deregulated in ILD due to exposure to organic matter in ambient air pollution [58]. There is a complex relation between the PM and TGF- $\beta$; the latter is suspected to be responsible for disordered protein synthesis, which in turn leads to ILD. TGF- $\beta$ is the target molecule for various drugs studied for the treatment of IPF.

Each of these three mechanisms may work singly or in conjugation to bring out the manifestations of ILD; which would also depend on the genetic and environmental predispositions of the person. More research and data are needed to understand the pathophysiology and association of air pollution with each individual subtype of ILD.

The term "exposome" has been used to denote the lifetime of exposures including inutero exposures. A similar concept was used earlier to study the risk factors associated in causation of cancer in patients. The term "exposome" was coined to supplement the genetic make-up of a patient to study the risk factors present in malignancy patients [59]. It constituted a collective term to denote all the environmental risk factors a person comes in contact with during their entire lifetime. Subsequently, the term exposome has been used in determining a patient's risk factors leading to various diseases like diabetes mellitus and psychiatric illnesses [60-64]. Ideally, exposome constitutes all the exposures a person encounters from his or her birth to death. The 
cumulative effect of lifetime exposures is more likely seen in IPF, as this disease is seen in elderly [65]. It is difficult to evaluate the exposome of a patient directly; it may be gauged indirectly with the help of biomarkers. The identification of suspected exposures and assessing for the associated biomarkers should be an integral part of evaluation of ILD patients. Biomarkers that are used as the telltale signs of exposure to air pollution include exhaled nitric oxide, induced sputum samples for microRNA, buccal mucosa cell examination for micronuclei frequency, serum IL-6 levels, and searching for exhaled breath condensate malondialdehyde [66-68]. However, more novel biomarkers need to be studied to assess the exposures a patient has over their lifetime.

\section{CONCLUSIONS AND FUTURE DIRECTIONS}

Exposure to air pollution exists from in utero, therefore discovering the environmental causes and searching for their biomarkers is thus needed. Population-based studies for the identification and measurement of exposome linked to IPF and other ILDs should be sought. More data are required to study the gene-environment interaction in order to apply this scientific data to clinical practice. Furthermore, studies are also required to depict if removal of the environmental factors affects the prognosis of the patients. This is particularly relevant in the clinical context of genetically susceptible individuals who are exposed to varied environmental agents including air pollution. As air pollution is quantifiable and its exposure is present throughout life, it is essential to document the association of markers of air pollution with ILD. Limiting exposure to poor quality air, which is a modifiable risk factor, can possibly prevent a reversible disease progressing to an irreversible and fibrotic form. These findings have significant public health impact. Efforts in the direction to control it both at the government and individual levels need to be instituted. Certain precautions should be followed in patients with ILDs to limit the exposure to air pollutants such as the use of facemasks, limiting outdoor activities, and limiting exercises on bad air-quality days [69].

\section{ACKNOWLEDGEMENTS}

Funding. No funding or sponsorship was received for this study or publication of this article.

Authorship. All named authors meet the International Committee of Medical Journal Editors (ICMJE) criteria for authorship for this article, take responsibility for the integrity of the work as a whole, and have given their approval for this version to be published.

Prior Presentation. Presentation on interstitial lung disease and air pollution was done during virtual ERS 2020 on 8th September.

Disclosures. Nishtha Singh and Sheetu Singh have nothing to disclose.

Compliance with Ethics Guidelines. This article is based on previously conducted studies and does not contain any studies with human participants or animals performed by any of the authors.

Open Access. This article is licensed under a Creative Commons Attribution-NonCommercial 4.0 International License, which permits any non-commercial use, sharing, adaptation, distribution and reproduction in any medium or format, as long as you give appropriate credit to the original author(s) and the source, provide a link to the Creative Commons licence, and indicate if changes were made. The images or other third party material in this article are included in the article's Creative Commons licence, unless indicated otherwise in a credit line to the material. If material is not included in the article's Creative Commons licence and your intended use is not permitted by statutory regulation or exceeds the permitted use, you will need to obtain permission directly from the copyright holder. To view 
a copy of this licence, visit http:// creativecommons.org/licenses/by-nc/4.0/.

\section{REFERENCES}

1. Cordeiro CR, Jones JC, Alfaro T, Ferreira AJ. Bronchoalveolar lavage in occupational lung diseases. Semin Respir Crit Care Med. 2007;28(5):504-13.

2. Baumgartner KB, Samet JM, Stidley CA, et al. Cigarette smoking: a risk factor for idiopathic pulmonary fibrosis. Am J Respir Crit Care Med. 1997;155:242-8.

3. Hubbard R, Lewis S, Richards K, et al. Occupational exposure to metal or wood dust and aetiology of cryptogenic fibrosing alveolitis. Lancet. 1996;347: 284-9.

4. World Health Organisation. Burden of disease from ambient air pollution for 2012. Geneva: World Health Organisation, Public Health, Social and Environmental Determinants of Health Department; 2014.

5. World Health Organisation. WHO releases country estimates on air pollution exposure and health impact 2016. http://www.who.int/mediacentre/ news/releases/2016/air-pollution-estimates/en/. Accessed 16th March 2017.

6. Global Burden of Disease 2013 Risk Factors Collaborators, Forouzanfar $\mathrm{MH}$, Alexander L, et al. Global, regional, and national comparative risk assessment of 79 behavioural, environmental and occupational, and metabolic risks or clusters of risks in 188 countries, 1990-2013: a systematic analysis for the Global Burden of Disease Study 2013. Lancet. 2015;386(10010):2287-323.

7. Genc S, Zadeoglulari Z, Fuss SH, Genc K. The adverse effects of air pollution on the nervous system. J Toxicol. 2012; 2012:782462.

8. Kelly FJ, Fussell JC. Air pollution and airway disease. Clin Exp Allergy. 2011;41(8):1059-71.

9. Faustini A, Stafoggia M, Colais P, et al. Air pollution and multiple acute respiratory outcomes. Eur Respir J. 2013;42(2):304-13.

10. Watson KE. Air pollution and heart disease. Rev Cardiovasc Med. 2006; 7(1):44.

11. Winterbottom CJ, Shah RJ, Patterson KC, et al. Exposure to ambient particulate matter is associated with accelerated functional decline in idiopathic pulmonary fibrosis. Chest. 2018;153:1221-8.
12. Kim D, Chen Z, Zhou LF, Huang SX. Air pollutants and early origins of respiratory diseases. Chronic Dis Transl Med. 2018;4(2):75-94.

13. Hime NJ, Marks GB, Cowie CT. A comparison of the health effects of ambient particulate matter air pollution from five emission sources. Int J Environ Res Public Health. 2018;15(6):1206. https://doi.org/ 10.3390/ijerph15061206.

14. Morman SA, Plumlee GS. Dust and human health, in P. Knippertz, J.B.W. Stuut (eds), Mineral dust: a key player in the earth system. Springer. 2014, 385-409.

15. Neff JC, Reynolds RL, Munson SM, Fernandez D, Belnap J. The role of dust storms in total atmospheric particle concentrations at two sites in the western U.S. J Geophys Res. 2013;118:201-11.

16. de Kok TMCM, Driece HAL, Hogervost JGF, Briede JJ. Toxicological assessment of ambient and trafficrelated particulate matter: a review of recent studies. Mutat Res. 2006;613:103-22.

17. Ayyagari VN, Januszkiewicz A, Nath J. Pro-inflammatory responses of human bronchial epithelial cells to acute nitrogen dioxide exposure. Toxicology. 2004;197:149-64.

18. Solomon C, Christian DL, Chen LL, et al. Effect of serial-day exposure to nitrogen dioxide on airway and blood leukocytes and lymphocyte subsets. Eur Respir J. 2000;15(5):922-8.

19. Frampton MW, Boscia J, Roberts NJ Jr, et al. Nitrogen dioxide exposure: effects on airway and blood cells. Am J Physiol Lung Cell Mol Physiol. 2002;282: L155-65.

20. Alexis NE, Lay JC, Hazucha M, et al. Low-level ozone exposure induces airways inflammation and modifies cell surface phenotypes in healthy humans. Inhal Toxicol. 2010;22(7):593-600.

21. Scannell C, Chen L, Aris RM, et al. Greater ozoneinduced inflammatory responses in subjects with asthma. Am J Respir Crit Care Med. 1996;154(1): 24-9.

22. Song H, Tan W, Zhang X. Ozone induces inflammation in bronchial epithelial cells. J Asthma. 2011;48(1):79-83.

23. Larsen ST, Matsubara S, McConville G, Poulsen SS, Gelfand EW. Ozone increases airway hyperreactivity and mucus hyperproduction in mice previously exposed to allergen. J Toxicol Environ Health A. 2010;73(11):738-47.

24. Nawrot TS, Vos R, Jacobs L, et al. The impact of traffic air pollution on bronchiolitis obliterans 
syndrome and mortality after lung transplantation. Thorax. 2011;66(9):748-54.

25. Ruttens D, Verleden SE, Bijnens EM, et al. An association of particulate air pollution and traffic exposure with mortality after lung transplantation in Europe. Eur Respir J. 2017;49:1600484.

26. Benmerad M, Slama R, Botturi K, et al. Chronic effects of air pollution on lung function after lung transplantation in the Systems prediction of Chronic Lung Allograft Dysfunction (SysCLAD) study. Eur Respir J. 2017;49:1600206.

27. Raghu G, Collard HR, Egan JJ, et al. ATS/ERS/JRS/ ALAT Committee on Idiopathic Pulmonary Fibrosis. An official ATS/ERS/JRS/ALAT statement: idiopathic pulmonary fibrosis: evidence-based guidelines for diagnosis and management. Am J Respir Crit Care Med. 2011;183(6):788-824.

28. King TE Jr, Pardo A, Selman M. Idiopathic pulmonary fibrosis. Lancet. 2011;378(9807):1949-61.

29. Iwai K, Mori T, Yamada N, Yamaguchi M, Hosoda Y. Idiopathic pulmonary fibrosis. Epidemiologic approaches to occupational exposure. Am J Respir Crit Care Med. 1994;150(3): 670-75.

30. Raghu G, Weycker D, Edelsberg J, Bradford WZ, Oster G. Incidence and prevalence of idiopathic pulmonary fibrosis. Am J Respir Crit Care Med. 2006; 174(7):810-16.

31. Society AT. American Thoracic Society. Idiopathic pulmonary fibrosis: diagnosis and treatment. International consensus statement. American Thoracic Society (ATS), and the European Respiratory Society (ERS). Am J Respir Crit Care Med. 2000;161: 646-64.

32. Sesé L, Nunes H, Cottin V, et al. Role of atmospheric pollution on the natural history of idiopathic pulmonary fibrosis. Thorax. 2018;73:145-50.

33. Johannson KA, Vittinghoff E, Lee K, et al. Acute exacerbation of idiopathic pulmonary fibrosis associated with air pollution exposure. Eur Respir J. 2014;43:1124-31.

34. Richards TJ, Kuhlengel TK, Choi J, Kaminski N, Bascom R. Does ambient air pollution exposure modify longitudinal disease outcomes in a cohort of patients with idiopathic pulmonary fibrosis? Am J Respir Crit Care Med. 2011;183:A5433.

35. Harari S, Raghu G, Caminati A, et al. Fibrotic interstitial lung diseases and air pollution: a systematic literature review. Eur Respir Rev. 2020;29: 200093.
36. Conti S, Harari S, Caminati A, et al. The association between air pollution and the incidence of idiopathic pulmonary fibrosis in Northern Italy. Eur Respir J, 2018. 51(1).

37. Johannson KA, Vittinghoff E, Morisset J, et al. Air pollution exposure is associated with lower lung function, but not changes in lung function, in patients with idiopathic pulmonary fibrosis. Chest. 2018;154(1):119-25.

38. Selman M, Pardo A, King TE Jr. Hypersensitivity pneumonitis: insights in diagnosis and pathobiology. Am J Respir Crit Care Med. 2012;186:314-24.

39. Karakatsani A, Papakosta D, Rapti A, et al. Epidemiology of interstitial lung diseases in Greece. Respir Med. 2009;103:1122-9.

40. Musellim B, Okumus G, Uzaslan E, et al. Epidemiology and distribution of interstitial lung diseases in Turkey. Clin Respir J. 2014;8:55-62.

41. Alhamad EH. Interstitial lung diseases in Saudi Arabia: a single-center study. Ann Thorac Med. 2013;8:33-7.

42. Singh S, Collins BF, Bairwa M, et al. Hypersensitivity pneumonitis and its correlation with ambient air pollution in urban India. Eur Respir J. 2019;53: 1801563.

43. Singh S, Collins BF, Sharma BB, et al. Interstitial lung disease in India. Results of a Prospective Registry. Am J Respir Crit Care Med. 2017;195:801-13.

44. Calderon-Garciduenas L, Mora-Tiscareno A, Fordham LA, et al. Lung radiology and pulmonary function of children chronically exposed to air pollution. Environ Health Perspect. 2006;114(9): 1432-7.

45. Sack C, Vedal S, Sheppard L, et al. Air pollution and subclinical interstitial lung disease: the Multi-Ethnic Study of Atherosclerosis (MESA) air-lung study. Eur Respir J. 2017;50(6):1700559.

46. Rice MB, Li W, Schwartz J, et al. Ambient air pollution exposure and risk and progression of interstitial lung abnormalities: the Framingham Heart Study. Thorax. 2019;74(11):1063-9.

47. Last JA, Reiser KM, Tyler WS, Rucker RB. Long-term consequences of exposure to ozone I. Lung collagen content. Toxicol Appl Pharmacol. 1984;72(1): 111-8.

48. Reiser KM, Tyler WS, Hennessy SM, Dominguez JJ, Last JA. Long-term consequences of exposure to ozone. II. Structural alterations in lung collagen of monkey. Toxicol Appl Pharmacol. 1987;89(3): 314-22. 
49. Devlin RB, Duncan KE, Jardim M, Schmitt MT, Rappold AG, Diaz-Sanchez D. Controlled exposure of healthy young volunteers to ozone causes cardiovascular effects. Circulation. 2012;126(1): 104-11.

50. Neophytou AM, Hart JE, Cavallari JM, et al. Trafficrelated exposures and biomarkers of systemic inflammation, endothelial activation and oxidative stress: a panel study in the US trucking industry. Environ Health. 2013;12:105.

51. Patel MM, Chillrud SN, Deepti KC, Ross JM, Kinney PL. Traffic related air pollutants and exhaled markers of airway inflammation and oxidative stress in New York City adolescents. Environ Res. 2013;121:71-8.

52. Grahame TJ, Schlesinger RB. Oxidative stress-induced telomeric erosion as a mechanism underlying airborne particulate matter related cardiovascular disease. Part Fibre Toxicol. 2012;9: 21.

53. Beeh KM, Beier J, Haas IC, Kornmann O, Micke P, Buhl R. Glutathione deficiency of the lower respiratory tract in patients with idiopathic pulmonary fibrosis. Eur Respir J. 2002;19(6):1119-23.

54. Martinez FJ, de Andrade JA, Anstrom KJ, King TE Jr, Raghu G. Idiopathic Pulmonary Fibrosis Clinical Research Network. Randomized trial of acetylcysteine in idiopathic pulmonary fibrosis. N Engl J Med. 2014; 370(22):2093-101.

55. Hou L, Wang S, Dou C, et al. Air pollution exposure and telomere length in highly exposed subjects in Beijing, China: a repeated measure study. Environ Int. 2012;48:71-7.

56. Alder JK, Chen JJ, Lancaster L, et al. Short telomeres are a risk factor for idiopathic pulmonary fibrosis. Proc Natl Acad Sci U S A. 2008;105(35):13051-6.

57. Garcia CK. Idiopathic pulmonary fibrosis: update on genetic discoveries. Proc Am Thorac Soc. 2011;8(2):158-62.

58. Libalova $\mathrm{H}$, Uhliřova $\mathrm{K}$, Klema J, et al. Global gene expression changes in human embryonic lung fibroblasts induced by organic extracts from respirable air particles. Part FibreToxicol. 2012;9:1.
59. Wild CP. Complementing the genome with an "exposome": the outstanding challenge of environmental exposure measurement in molecular epidemiology. Cancer Epidemiol Biomark Prevent. 2005;14(8):1847-50.

60. Patel CJ, Bhattacharya J, Butte AJ. An EnvironmentWide Association Study (EWAS) on type 2 diabetes mellitus. PLoS ONE. 2010;5(5):e10746 .

61. Sands BE. Within you, without you: is gastroenterology ready to embrace the "exposome"? Gastroenterology. 2012;142(7):1403-4.

62. Stahler GJ, Mennis J, Baron DA. Geospatial technology and the "exposome": new perspectives on addiction. Am J Public Health. 2013;103(8):1354-6.

63. Buck Louis GM, Yeung E, Sundaram R, Laughon SK, Zhang C. The exposome-exciting opportunities for discoveries in reproductive and perinatal epidemiology. Paediatr Perinat Epidemiol. 2013;27(3): 229-36.

64. Rappaport SM, Smith MT. Epidemiology. Environment and disease risks. Science. 2010;330(6003): $460-1$.

65. Fell CD, Martinez FJ, Liu LX, et al. Clinical predictors of a diagnosis of idiopathic pulmonary fibrosis. Am J Respir Crit Care Med. 2010;181(8):832-7.

66. Gong J, Zhu T, Kipen H, et al. Malondialdehyde in exhaled breath condensate and urine as a biomarker of air pollution induced oxidative stress. J Expo Sci Environ Epidemiol. 2013;23(3):322-7.

67. Ceretti E, Feretti D, Viola GC, et al. DNA damage in buccal mucosa cells of pre-school children exposed to high levels of urban air pollutants. PLOS ONE. 2014;9(5):e96524.

68. Berhane K, Zhang Y, Salam MT, et al. Longitudinal effects of air pollution on exhaled nitric oxide: the Children's Health Study. Occup Environ Med. 2014;71(7):507-13.

69. Johannson KA, Balmes JR, Collard HR. Air pollution exposure: a novel environmental risk factor for interstitial lung disease? Chest. 2015;147(4): 1161-7. 